\title{
HUBUNGAN ANTARA KECERDASAN EMOSI DENGAN FORGIVENESS PADA REMAJA YANG PUTUS CINTA AKIBAT PERSELINGKUHAN
}

\author{
Anselma Tesalonika Demosta Beloved Purba ${ }^{1}$, Ratriana Y.E Kusumawati ${ }^{2}$ \\ Email : anselmatesalonika31@gmail.com ${ }^{1}$ \\ Fakultas Psikologi, Universitas Kristen Satya Wacana ${ }^{1,2}$
}

\begin{abstract}
Abstrak
Putus cinta akibat perselingkuhan merupakan salah satu kasus mengapa remaja sulit untuk memberikan pemaafan pada orang yang telah menyakitinya.Maka dari itu perlu adanya kecerdasan emosi pada remaja sebagai upaya melepaskan unforgiveness dan dapat berdamai dengan orang yang telah menyakitinya. Sampel penelitian ini sejumlah 137 subjek yang pernah mengalami putus cinta akibat perselingkuhan yang diperoleh melalui teknik snowball sampling. Alat ukur yang digunakan dalam penelitian ini adalah skala Transgression Related Interpersonal Motivation Inventory (TRIM-18) dengan koefisian alpa cronbach sebesar 0,891 dan skala kecerdasan emosi dengan koefisien alpha cronbach sebesar 0,771. Dari hasil analisis data diperoleh hasil koefisien korelasi $r=0,305$ dengan signifikansi sebesar $0,000(p \leq 0,05)$ yang berarti terdapat hubungan yang signifikan antara forgiveness dengan kecerdasan emosi pada remaja yang putus cinta akibat perselingkuhan,sehingga hipotesis yang diajukan dalam penelitian ini diterima.
\end{abstract}

Kata kunci : Kecerdasan Emosi; Forgiveness.

\begin{abstract}
Breakup that caused by infidelity is one of the reason why teens can not admit the apology from someone who had hurt them. Therefore, emotional intelligence is indispensable for teenagers as the effort to let the unforgiveness go and able to be at peace with the person who hurt them. This research sample amount to 137 subjects that had a breakup which caused by infidelity that obtained by snowball sampling method. The measuring instrument that used in this research is Transgression Related Interpersonal Motivation Inventory scale (TRIM-18) with cronbach's alpha coefficient of 0,891 and the emotion intelligence scale of 0,771. From the result of data analysis, the correlation coefficient $r=0,305$ and significant of $0,000(<0,05)$ that means there is a significant connection between forgiveness and emotional intelligence in the teenagers who had a breakup that caused by infidelity, so that the hypothesis proposed in this research can be accepted.
\end{abstract}

Key Words: Emotional Intelligence; Forgiveness

\section{PENDAHULUAN}

Remaja adalah individu dengan rentang usia 18-24 tahun yang sedang mengalami tahap masa perkembangan (Malahayati,2010). Masa remaja merupakan masa-masa yang paling indah dalam fase kehidupan manusia, karena pada masa remaja, individu akan mulai bergaul dengan banyak orang, membentuk persahabatan dengan teman dan mulai menyukai lawan jenis (Feist,2013). Garrison (1946) menyebutkan salah satu tugas perkembangan remaja adalah menjalin hubungan baru dengan teman-teman sebaya yang berlawanan jenis (pacaran). Pacaran atau menjalin hubungan romantis menurut Santrock (2007) sudah terbentuk pada tahun 1920-an, dimana saat itu fungsi utama pacaran adalah untuk memilih dan mendapatkan seorang pasangan. Miller (2015) mengatakan relationship merupakan suatu proses yang penuh dengan perubahan, seperti 
perubahan mood hingga kondisi kesehatan. Perubahan-perubahan yang terjadi dalam menjalin hubungan tentu bisa saja sampai pada berakhirnya hubungan tersebut.

Duck (1982) mengatakan bahwa pemutusan suatu hubungan (relationship dissolution) merupakan hal yang normal terjadi dalam dinamika hubungan intim. Putus cinta didefinisikan sebagai sebuah kejadian berakhirnya suatu hubungan cinta yang telah dijalin dengan pasangannya.Yuwanto mengatakan bahwa seseorang yang masih mencintai pasangannya dan kemudian mengalami putus cinta biasanya akan menampilkan suatu reaksi kehilangan, terutama diawal putus cinta. Penyebab putus cinta sangat banyak, salah satunya karena perselingkuhan.Johnson (2005) mendefinisikan perselingkuhan sebagai tindakan yang dirasakan dan dialami sebagai penghianatan yang menyakitkan dari suatu kepercayaan dan ancaman dalam suatu hubungan; tindakan ini merusak ikatan kasih sayang dan cinta pada pasangan.

Sebuah fenomena yang terjadi pada tanggal 28 Desember 2014 dikutip dari berita harian Kompas meliput kasus seorang remaja putri bernama Bellinda ditemukan meninggal dunia di perlintasan kereta api, diduga ia sengaja bunuh diri karena putus dari pacarnya setelah mengalami percekcokan. Penjelasan dari ayah korban bahwa anaknya bercekcok karena pacarnya berselingkuh, tidak terima dengan hal itu, keeoskan harinya korban menabrakan diri di lintasan KRL.Tidak semua remaja mampu berpikir rasional dan memiliki pertimbangan matang serta pemikiran yang jernih dalam menghadapi suatu masalah.Remaja yang pernah diselingkuhi tentunya merasakan kesedihan yang mendalam, sulit menerima kenyataan, merasa menderita, tidak merasa bahagia, sedih, tidak dapat berfikir jernih. Hal tersebut membuat remaja melakukan tindakan-tindakan negatif yang tidak diharapkan dan lain sebagainya. Tindakan tersebut merupakan hal yang wajar ketika ditimpa masalah putus cinta, tetapi apabila kadarnya sudah berlebihan seperti sedih yang berlarutlarut selama beberapa bulan atau penyesalan yang tak kunjung hilang serta stres yang hingga mengganggu konsentrasi belajar, tentu dapat menjadi sebuah masalah besar bagi remaja.

Menurut Worthington \& Wade (1999) pengalaman emosi yang marah, benci, dan meledak-ledak yang terjadi pada orang yang telah mengalami peristiwa yang perih, mengiris, dan melukai hati disebut dengan 
unforgiveness. Seseorang yang mengalami unforgiveness seyogyanya mempertimbangkan untuk melakukan forgivenesssebagai upaya melepaskan unforgiveness dan berdamai dengan orang yang telah menyakitinya. Oleh karena itu remaja memerlukan proses penyembuhan luka dengan melakukan forgiveness terhadap orang yang telah menyakitinya agar memunculkan rasa damai dan bahagia.

$$
\text { McCullough }
$$

mengemukakan bahwa memaafkan merupakan seperangkat motivasi untuk mengubah seseorang untuk tidak membalas dendam dan meredakan dorongan untuk memelihara kebencian terhadap pihak yang menyakiti serta meningkatkan dorongan untuk konsiliasi hubungan dengan pihak yang menyakiti.

Enright (1991) mendefinisikan memaafkan sebagai sikap untuk mengatasi hal-hal yang negative dan penghakiman terhadap orang yang bersalah dengan tidak menyangkal rasa sakit itu sendiri tetapi dengan rasa kasihan, iba dan cinta kepada pihak yang menyakiti. Kesediaan dari seseorang untuk memaafkan dipengaruhi oleh faktor-faktor tertentu, menurut Worthington dan Wade (1999) faktorfaktor yang mempengaruhi forgiveness salah satunya adalah kecerdasan emosi.
Kecerdasan emosional menurut Chaplin (2002) adalah kondisi atau keadaan dalam mencapai tingkat kedewasaan dalam perkembangan emosional seseorang. Kecerdasan emosi membantu remaja yang putus cinta untuk memahami dirinya sendiri, memahami perasaan orang lain serta dapat mempertanggungjawabkan segala perbuatannya sehingga remaja yang putus cinta yang memliki kecerdasan emosi akan mengatasi permasalahan dengan baik yang datang dalam diri ataupun dari luar diri.

Berdasarkan penelitian sebelumnya yang dilakukan oleh Lidia (2016) mengatakan bahwa adanya hubungan antara Kecerdasan Emosi dan Forgiveness. Hasil yang berbeda dilakukan oleh Mugrage (2014) ia mengatakan bahwa hasil penelitian ini tidak memberikan bukti hubungan yang berkorelasi positif antara kecerdasan emosional dan forgiveness. Hasil wawancara dengan 2 subjek pada remaja yang putus cinta karena perselingkuhan, mereka merasa putus cinta adalah hal terberat untuk dilalui. Rasa penghianatan begitu dalam terasa oleh korban.Mereka mengakui bahwa butuh waktu yang cukup panjang dalam mengembalikan mood yang stabil. 
Melihat fenomena yang ada dilapangan dan juga teori yang ada ,dapat disumpulkan banyak remaja yang tidak bisa mengontrol dirinya ketika sedang putus cinta, adanya rasa marah dan dendam dalam hati, juga membutuhkan kecerdasan emosi dalam menyelesaikan permasalahan. Maka dari fenomena ini menarik peneliti untuk mengangkat sebuah penelitian dengan judul "Hubungan antara Kecerdasan Emosi dan Forgiveness pada Remaja yang putus cinta akibat perselingkuhan".

\section{METODE PENELITIAN}

Jenis penelitian yang digunakan adalah penelitian kuantitatif dengan desain korelasional. Variabel bebas dalam penelitian ini adalah kecerdasan emosi, sedangkan variabel terikat adalah forgiveness. Definisi operasional setiap variabel dapat dijelaskan sebagai berikut:

\section{Forgiveness}

McCullough (2000) mendefinisikan forgiveness sebagai perubahan serangkaian perilaku dengan jalan menurunkan motivasi untuk membalas dendam,menjauhkan diri atau menghindar dari pelaku. Variabel forgiveness diukur dengan Transregression-Related Interpersonal Motivation (TRIM) inventory (TRIM-18) yang dibuat oleh McCullough, Root, \& Cohen (2006) yang mengacu pada aspek (a) Avoidance Motivations, (b) Revenge Motivations, (c) Beneviolence motivation. Kecerdasan Emosi

Goleman (2000) mengatakan kecerdasan emosi adalah kemampuan untuk mengendalikan diri,memiliki daya tahan ketika menghadapi suatu masalah, mampu mengendalikan impuls, memotivasi diri, mampu mengatur suasana hati, kemampuan berempati dan membina hubungan dengan orang lain.Variabel kecerdasan emosi diukur dengan berpedoman dengan kajian teori mengenai aspek kecerdasan emosi dan disesuaikan dengan teori Goleman (2000) yang mengacu pada aspek (a) mengenali emosi diri, (b) mengelola emosi, (c) memotivasi diri sendiri, (d) mengenali emosi orang lain, (e) membina hubungan.

Partisipan dalam penelitian ini berjumlah 137 orang. Teknik pengambilan sampel yang digunakan adalah snowball sampling,dimana partisipan diambil sesuai dengan kriteria yang sudah ditentukan sebelumnya yaitu : (a) pernah mengalami putus cinta akibat perselingkuhan (b) berusia 18-24 tahun, (c)rentang usia putus cinta selama 1 tahun -3 tahun.

Alat ukur dalam penelitian ini menggunakan dua skala, yaitu skala forgiveness dan skala kecerdasan emosi. Alat ukur yang digunakan untuk 
mengukur forgiveness adalah Transregression-Related Interpersonal Motivation (TRIM) inventory (TRIM-18) yang dibuat oleh McCullough, Root, \& Cohen (2006) dengan menerapkan teori forgiveness McCullough, Root, \& Cohen (2006) kemudian diadaptasi oleh peneliti ke dalam bahasa Indonesia dan disesuaikan dengan kepentingan penelitian. Alat ukur yang digunakan untuk mengukur kecerdasan emosi adalah skala yang dibuat dengan berpedoman pada kajian teori mengenai aspek kecerdasan emosi dan disesuaikan berdasakn teori Goleman (2000).

Skala forgiveness memiliki 21 aitem, dengan empat pilihan jawaban yaitu Sangat Tidak Sesuai (STS), Tidak Sesuai (TS), Sesuai (S), Sangat Sesuai (SS). Berdasarkan uji realibilitas, nilai yang didapat adalah 0,327 dengan koefisien Cronbach's alpa sebesar 0,891 sehingga skala psikologi dalam variabel forgiveness dinyatakan reliabel.

Skala kecerdasan emosi memiliki 40 aitem, dengan empat pilihan jawaban yaitu Sangat Tidak Sesuai (STS), Tidak Sesuai (TS), Sesuai (S), Sangat Sesuai (SS). Setelah dilakukan diskriminasi aitem melalui corrected item-total correlation diperoleh aitem yang gugur sebanyak 1 aitem dan didiskriminasi baik sebanyak 39 aitem,adapun aitem yang gugur tersebut adalah aitem nomor: 8 . Berdasarkan hasil uji realibilitas, diketahui bahwa aitem kecerdasan emosi dari 40 aitem menjadi 39 aitem memiliki nilai diskrimasi aitem bergerak dari 0,491 menjadi 0,515 dengan koefisien Cronbach's alpa sebesar 0,717 sehingga skala psikologi dalam variabel kecerdasan emosi dinyatakan reliabel. Metode analisis data yang digunakan adalah teknik correlation product moment dari Karl Pearson,dengan bantuan program statistic SPSS versi 18.0 for windows.

\section{HASIL PENELITIAN}

Hasil analisis deskriptif terhadap variabel forgiveness dan variabel kecerdasan emosi diperoleh hasil sebagai berikut: (a) sebesar $59,9 \%$ subyek memiliki pemaafan dengan kategori sedang, (b) sebesar 86,9\%, subyek memiliki kecerdasan emosi dengan kategori sedang. Hasil pengkategorian selengkapnya dapat dilihat pada tabel dibawah ini:

Tabel 1.Kategori Hasil pengukuran Skala Forgiveness

\begin{tabular}{lllllll}
\hline No. & Interval & Kategori & F & $\%$ & Mean & SD \\
\hline $\mathbf{1}$ & $90,2 \leq x<106$ & Sangat tinggi & 0 & $0 \%$ & & \\
\hline $\mathbf{2}$ & $73,4 \leq x<89,2$ & Tinggi & 11 & $8.03 \%$ & 59.88 & 10.237 \\
\hline $\mathbf{3}$ & $56,6 \leq x<72,4$ & Sedang & 82 & $59.9 \%$ & & \\
\hline $\mathbf{4}$ & $38,8 \leq x<55,6$ & Rendah & 42 & $30.7 \%$ & & \\
\hline $\mathbf{5}$ & $21 \leq x<37,8$ & Sangat Rendah & 2 & $1.46 \%$ & \\
\hline & Total & & 137 & $100 \%$ &
\end{tabular}


Tabel 2. Kategori Hasil pengukuran Skala Kecerdasan Emosi

\begin{tabular}{lllllll}
\hline No. & Interval & Kategori & F & $\%$ & Mean & SD \\
\hline 1 & $167,0 \leq x<198,8$ & Sangat tinggi & 0 & $0 \%$ & & \\
\hline $\mathbf{2}$ & $135,4 \leq x<166,6$ & Tinggi & 4 & $2.92 \%$ & 116.30 & 10.367 \\
\hline $\mathbf{3}$ & $103,2 \leq x<134,4$ & Sedang & 119 & $86.9 \%$ & \\
\hline 4 & $71,2 \leq x<102,4$ & Rendah & 14 & $10.2 \%$ & \\
\hline $\mathbf{5}$ & $39 \leq x<70,2$ & Sangat Rendah & 0 & $0 \%$ & \\
\hline & Total & & 137 & $100 \%$ &
\end{tabular}

Penelitian ini menggunakan uji normalitas yang bertujuan untuk mengetahui normal atau tidaknya distribusi data penelitian pada masingmasing variabel dan menggunakan uji linearitas. Dari hasil uji normalitas bahwa sampel berdistribusi normal, pada variabel forgiveness diperoleh $\mathrm{K}-\mathrm{S}-\mathrm{Z}$ 0.950, nilai sig.0.372( $\mathrm{p}>0,05)$, pada variabel kecerdasan emosi diperoleh K-SZ 0.818, nilai sig. 0.515 ( $\mathrm{p}>0,05$ ). Hasil uji linearitas menunjukan adanya hubungan yang linear antara kecerdasan emosi dengan forgiveness dengan deviation from linearity sebesar $\mathrm{F}$ beda= $1.369 \mathrm{p}=0.106$.

Tabel 3. Uji Linearitas

\begin{tabular}{|c|c|c|c|c|c|c|c|}
\hline & & & $\begin{array}{l}\text { Sum of } \\
\text { Squares }\end{array}$ & Df & $\begin{array}{l}\text { Mean } \\
\text { Square }\end{array}$ & F & Sig. \\
\hline \multirow{11}{*}{$\begin{array}{l}\text { forgiveness } \\
\text { kecerdasan } \\
\text { emosi }\end{array}$} & \multirow{7}{*}{$\begin{array}{l}* \text { Between } \\
\text { Groups }\end{array}$} & \multirow[t]{2}{*}{ (Combined) } & 6265.9 & \multirow[t]{2}{*}{43} & 145.71 & 1.69 & \multirow[t]{2}{*}{.018} \\
\hline & & & 19 & & 9 & 7 & \\
\hline & & \multirow[t]{2}{*}{ Linearity } & 1327.1 & \multirow[t]{2}{*}{1} & 1327.1 & 15.4 & \multirow[t]{2}{*}{.000} \\
\hline & & & 27 & & 27 & 54 & \\
\hline & & \multirow{3}{*}{$\begin{array}{l}\text { Deviation } \\
\text { from } \\
\text { Linearity }\end{array}$} & 4938.7 & \multirow[t]{3}{*}{42} & 117.59 & 1.36 & \multirow[t]{3}{*}{.106} \\
\hline & & & 92 & & 0 & 9 & \\
\hline & & & & & & & \\
\hline & \multirow{2}{*}{\multicolumn{2}{|c|}{ Within Groups }} & 7986.2 & 93 & 85.873 & & \\
\hline & & & 12 & & & & \\
\hline & \multirow{2}{*}{\multicolumn{2}{|c|}{ Total }} & 14252. & 136 & & & \\
\hline & & & 131 & & & & \\
\hline
\end{tabular}

Tabel 4. Uji Normalitas

\begin{tabular}{llll}
\hline One-Sample Kolmogorov-Smirnov Test & & \\
\hline & & forgiveness & $\begin{array}{l}\text { Kecerdasa } \\
\mathrm{n} \text { emosi }\end{array}$ \\
\cline { 2 - 4 } $\mathrm{N}$ & & 137 & 137 \\
Normal Parameters ${ }^{\mathrm{a}, \mathrm{b}}$ & Mean & 59.88 & 116.30 \\
& Std. Deviation & 10.237 & 10.367 \\
Most Extreme & Absolute & .081 & .070 \\
Differences & Positive & .067 & .070 \\
& Negative & -.081 & -.062 \\
Kolmogorov-Smirnov Z & & .950 & .818 \\
Asymp. Sig. (2-tailed) & & .327 & .515 \\
a. Test distribution is Normal. & &
\end{tabular}

Dari hasil uji asumsi yang menunjukan bahwa data yang diperoleh berdistribusi normal dan variabel-variabel penelitian linear, maka dalam penelitian ini menggunakan uji korelasi statistik parametik. Uji korelasi yang digunakan dalam penelitian ini adalah korelasi product moment pearson.

Hasil uji korelasi menunjukan bahwa ada hubungan positif signifikan antara kecerdasan emosi dengan forgiveness dengan $\mathrm{r}=0,305$ dengan nilai signifikan $0,000(\mathrm{p}<0,05)$ yang dapat diartikan hipotesis dalam penelitian ini diterima. Semakin tinggi kecerdasan emosi remaja yang putus cinta akibat perselingkuhan maka semakin tinggi tingkat forgiveness yang mereka miliki. Demikian sebaliknya, semakin rendah kecerdasan emosi yang dimiliki maka semakin rendah tingkat forgiveness yang mereka miliki. 
Tabel 5. Uji Korelasi

\begin{tabular}{llll} 
& & forgiveness & $\begin{array}{l}\text { kecerdasan } \\
\text { emosi }\end{array}$ \\
\hline Forgiveness & Pearson Correlation & 1 & $.305^{* *}$ \\
\cline { 2 - 4 } & Sig. (1-tailed) & .000 \\
\cline { 2 - 4 } & $\mathrm{N}$ & 137 & 137 \\
\hline kecerdasan emosi & Pearson Correlation & $.305^{* * *}$ & 1 \\
\cline { 2 - 4 } & Sig. (1-tailed) & .000 & \\
\cline { 2 - 4 } & $\mathrm{N}$ & 137 & 137 \\
\hline **. Correlation is significant at the 0.01 level (1-tailed) &
\end{tabular}

\section{PEMBAHASAN}

Berdasarkan penelitian mengenai hubungan kecerdasan emosi dengan forgiveness pada remaja yang putus cinta akibat perselingkuhan, didapatkan hasil adanya nilai korelasi positif yang signifikan antara kecerdasan emosi dengan forgiveness dengan demikian hipotesis diterima. Hasil hipotesis menunjukkan koofisien korelasi $(r)=0,305$ dengan sig.0,000 $(p<0,05)$,ini menunjukan bahwa semakin tinggi kecerdasan emosi pada seseorang, semakin mampu ia memaafkan orang lain yang menyakitinya.

Berdasarkan penelitian sebelumnya yang dilakukan oleh Lidia (2016) menemukan bahwa adanya hubungan antara Kecerdasan Emosi dan Forgiveness. Semakin tinggi kecerdasan emosi yang dimiliki siswa maka akan semakin tinggi pula forgiveness dalam diri seseorang. Menurut Worthington \& Wade (1999) kecerdasan emosi ini merupakan salah satu faktor yang dapat mempengaruhi seseorang untuk memaafkan, kemampuan dalam kecerdasan emosi yang dimaksud adalah untuk dapat memahami emosi diri sendiri dan orang lain. Menurut Mayer, Salovey, dan Caruso (dalam Hudgson dan Wertheim,2007) kemampuan mengelola emosi seseorang merupakan komponen tertinggi dari apa yang disebut dengan kecerdasan emosi, mereka yang mampu mengelola emosinya dengan terampil dapat memperlihatkan pegalaman emosional mereka yang menyebabkan kejelasan tentang emosi mana yang mereka alami. Kesadaran akan emosi seseorang dianggap sebagai dasar untuk mengatur atau memperbaiki emosi seseorang yang memungkinkan forgiveness terwujud.

Kecerdasan emosi yang dimiliki para remaja yang putus cinta akibat perselingkuhan akan menjadi sumber kemampuan dalam menciptakan emosi yang positif. Menurut Erez dan Isen (2002) keadaan positif membantu seseorang untuk menjadi lebih peka dalam penyelesaian masalah yang lebih fleksibel dan efektif,pengambilan keputusan dan mengevaluasi suatu peristiwa. Oleh karena itu emosi positif akan membantu remaja menjadi adaptif dan interaktif ketika berhubungan dengan permasalahan yang dihadapi. Dalam hal ini, emosi positif membantu remaja yang 
putus cinta akibat perselingkuhan untuk menghadapi dampak negatif yang mereka hadapi seperti stress, kesedihan yang berlarut ataupun kenangan berulang yang muncul tentang perselingkuhan. Adanya emosi positif sebagai komponen daripada kecerdasan emosi akan menimbulkan forgiveness pada remaja yang putus cinta akibat perselingkuhan. Forgiveness yang bersumber dari pada emosi positif akan membantu mereka melakukan coping yang baik.

$$
\text { Forgiveness pada remaja yang }
$$
diselingkuhi membantu mereka mengurangi tindakan negatif seperti balas dendam kepada pelaku,menghindar dari pelaku. Sejalan dengan apa yang dikemukakan oleh Enright (dalam Ariyanti,2017) mengelola emosi dengan cara positif seperti berperilaku yang baik, berempati ataupun memberikan rasa cinta dapat membantu menekan emosi negatif seperti kebencian,kemarahan penolakkan dan keinginan untuk membalas dendam sehingga individu menjadi mampu untuk memaafkan orang lain.

Kecerdasan emosi yang dimiliki remaja korban perselingkuhan dalam membangun hubungan yang baik dikarenakan adanya motivasi diri.Goleman, (2001) menjelaskan kemampuan motivasi diri didasari oleh kemampuan mengendalikan emosi, yaitu menahan diri terhadap kepuasan dan mengendalikan dorongan hati. Kemampuan ini meliputi: pengendalian dorongan hati, kekuatan berpikir positif dan optimis. Seseorang dapat memiliki kecerdasan emosi yang baik disebabkan adanya pengelolaan emosi yang baik pada individu tersebut.

Menurut Lopes et al., (2011) kemampuan pengelolaan emosi dianggap penting untuk kemampuan interpersonal karena emosi melayani fungsi komunikatif dan sosial sehingga seseorang dapat membangun relasi yang baik dengan orang lain.

Remaja yang putus cinta akibat perselingkuhan adalah salah satu pribadi yang perlu memiliki forgiveness dalam dirinya, agar memunculkan rasa damai dan bahagia (Worthington \& Wade,1999). Ditinjau dari pengambilan data, rata-rata kecerdasan emosi remaja yang putus cinta akibat perselingkuhan terdapat pada kategori sedang. Sama halnya dengan forgiveness rata-rata terdapat pada kategori sedang.

Berdasarkan uraian diatas,dapat diperoleh hasil bahwa kecerdasan emosi memiliki hubungan dengan forgiveness pada remaja yang putus cinta akibat perselingkuhan. Hal ini diketahui dari hasil penelitian yang menunjukkan bahwa 
hasil hipotesis yang diajukan telah terbukti atau diterima yaitu terdapat hubungan positif antara kecerdasan emosi dengan forgiveness pada remaja yang putus cinta akibat perselingkuhan.

Berdasarkan hasil uji korelasi, adapun sumbangan efektif yang diberikan kecerdasan emosi terhadap forgiveness sebesar 9,4\%. Artinya, masih ada 90,6\% faktor-faktor luar yang mempengaruhi forgiveness, seperti kualitas hubungan,respon pelaku, empati, rumination, komitmen agama dan faktor personal (Warthington \& Wade,1999)

\section{PENUTUP}

Berdasarkan penelitian yang telah dilakukan tentang hubungan kecerdasan emosi dengan forgiveness pada remaja yang putus cinta akibat perselingkuhan, maka dapat disimpulkan (a) Adanya hubungan yang positif signifikan antara kecerdasan emosi dengan forgiveness pada remaja akhir yang putus cinta akibat perselingkuhan. Semakin tinggi tingkat kecerdasan emosi remaja, maka semakin mampu ia memberikan forgiveness pada mantan kekasihnya. Sebaliknya, semakin rendah tingkat kecerdasan emosi remaja, maka semakin tidak mampu ia memberikan forgiveness pada mantan kekasihnya yang telah berselingkuh. (b) Rata-rata remaja yang memiliki kecerdasan emosi termasuk dalam kategori sedang,yaitu 59,9\%, sama halnya dengan forgiveness juga termasuk dalam kategori sedang,yaitu $86,9 \%$. (c) Sumbangan efektif yang diberikan kecerdasan emosi terhadap forgiveness pada remaja yang putus cinta akibat perselingkuhan adalah sebesar 9,4\%.

Berdasarkan pada hasil penelitian ini, peneliti memberikan saran kepada subjek penelitian dan kepada para peneliti selanjutnya. Kepada subjek penelitian diharapkan mampu memiliki hubungan sosial yang membangun seperti lingkungan keagamaan, organisasi yang dapat berdampak positif bagi agar memiliki kecerdasan emosi yang stabil dan lebih menghargai diri. Kepada peneliti selanjutnya dapat mengembangkan metode selain kuantitatif.Dapat pula ditambahkan variabel bebas yang dapat juga mempengaruhi forgiveness. Selain itu, perlunya observasi tempat pengambilan data, misalnya hanya dalam satu tempat atau satu kota saja, agar penyebaran angket penelitian merata dan subjek yang digunakan adalah selain remaja.

\section{DAFTAR PUSTAKA}

Chaplin. J.P. 2002. Kamus lengkap psikologi.CetakanKeenam. Penerjemah : Kartiko, K. Jakarta : PT. Raja Grafika Persada

Dessy,A.2014.http://megapolitan.kompas .com/read/2014/12/17/14172031/ 
putus.cinta.wanita.muda.ini.didug a.tabrakkan.diri.ke.KRL.Diaksesta nggal 17 Desember 2014.

Duck, S. 1982. A Topography of Relationship Disengagement And Dissolution. Personal relationships, 4, 1-30.

Enright, R. D. 1991. The Moral Development of Forgiveness.Handbook of moral behavior and development, 1, 123-152.

Feist, J., Feist. G. J. 2013. Teori Kepribadian Jilid 1. Jakarta Salemba.

Garrison, K. C.1946. The Psychology of Adolescence.

Gulo, W. 2002. Metodologi Penelitian. Jakarta: Grasindo.

Goleman, D., \& Widodo, A. T. K. 1999.Kecerdasan Emosi Untuk Mencapai Puncak Prestasi. Gramedia Pustaka Utama.

Husaini, U., \& Akbar, P. S. 1996. Metodologi Penelitian Sosial. Jakarta: Bumi Aksara.

Lidia, L. 2016. Hubungan Antara Kecerdasan Emosi Dengan Sikap Memaafkan Pada Siswa Kelas X Dan XI SMA Muhammadiyah 2 palembang (Skripsi) (Doctoral dissertation, UIN Raden Fatah Palembang)..

Mafiroh, Imaniah. 2015.Hubungan Antara Kecerdasan Emosi Dengan Perilaku Agresif Remaja Pada Siswa Kelas Xi Di Sma Negeri 1 Pleret Tahun Ajaran 2013/2014. Repositori UNY
Malahayati. 2010. Super teens. Yogyakarta: Jogja Bangkit Publisher

Miller, R. T., \& Janmey, P. A. 2015. Relationship Of And Cross-Talk Between Physical And Biologic Properties Of The Glomerulus. Current Opinion In Nephrology And Hypertension, 24(4), 393.

McCullough, M. E., Worthington Jr, E. L., \& Rachal, K. C. 1997. Interpersonal forgiving in close relationships. Journal of personality and social psychology, 73(2), 321.

Santrock, J. W. 2002. Adolescence. McGraw-Hill Companies. 2007. Psikologi Pendidikan (edisi kedua).(Penerj. Tri Wibowo B.S). Jakarta: Kencana.

Sevilla, C. G. dkk. 1993. Pengantar Metode Penelitian. Jakarta: UI Press

Sugiyono. 2011. Metode Penelitian Kuantitatif, Kualitatif dan $R \& D$. Bandung: Afabeta

Worthington Jr, E. L., \& Wade, N. G. 1999. The psychology of unforgiveness and forgiveness and implications for clinical practice. Journal of Social and clinical psychology, 18(4), 385418_.(2007). Handbook of forgiveness. Routledge

Yuwanto, L. 2011. Reaksi umum putus cinta. http://www.ubaya.ac.id/ ubaya/articles_detail/24/ReaksiU mum-Putus-Cinta.html. Diakses pada 28 Juni 2018 pukul 23:26 WIB. 